\title{
Investigation of the Variability and Implications of Meteorological Dry/Wet Conditions in the Poyang Lake Catchment, China, during the Period 1960-2010
}

\author{
Xu-chun Ye, ${ }^{1}$ Yun-liang Li, ${ }^{2}$ Xiang-hu Li, ${ }^{2}$ Chong-yu Xu, ${ }^{3}$ and Qi Zhang ${ }^{2,4}$ \\ ${ }^{1}$ School of Geographical Sciences, Southwest University, Chongqing 400715, China \\ ${ }^{2}$ Key Laboratory of Watershed Geographic Science, Nanjing Institute of Geography and Limnology, Chinese Academy of Sciences, \\ Nanjing 210008, China \\ ${ }^{3}$ Department of Geosciences, University of Oslo, P.O. Box 1047, Blindern, 0316 Oslo, Norway \\ ${ }^{4}$ Key Laboratory of Poyang Lake Wetland and Watershed Research, Ministry of Education, Jiangxi Normal University, \\ Jiangxi 330000, China \\ Correspondence should be addressed to Xu-chun Ye; yxch2500@163.com
}

Received 17 March 2015; Revised 30 June 2015; Accepted 1 July 2015

Academic Editor: Antonio Donateo

Copyright $\odot 2015 \mathrm{Xu}$-chun Ye et al. This is an open access article distributed under the Creative Commons Attribution License, which permits unrestricted use, distribution, and reproduction in any medium, provided the original work is properly cited.

\begin{abstract}
This paper presents a quantitative investigation of the variability of meteorological dry/wet conditions of the Poyang Lake catchment during 1960-2010 by using the standardized precipitation-evapotranspiration index (SPEI) based on daily observations of 14 meteorological stations across the catchment. Extending from previous studies, the background of the encounter and overlap of multitimescales of meteorological dry/wet episodes for several severe drought and flood events were discussed. In addition, the possible impacts of temperature changes on dry/wet variability were also examined by the comparison of SPEI and standardized precipitation index (SPI) variations at multitimescales during the study period. Major results show that the occurrence of dry/wet condition has become increasingly frequent in the recent two decades, especially the extreme wet episodes in 1990s and the extreme dry episodes in 2000s. Historically, the encounter and overlap of multitimescales of meteorological dry/wet episodes plays an important role in the occurrence of several severe drought and flood events. The study concluded that the impact of temperature anomaly to the dry/wet variability cannot be neglected.
\end{abstract}

\section{Introduction}

As global warming intensified hydrological cycle, spatial and temporal distribution of water resource have been changed all over the world, exerting tremendous influences on the ecological environment and agriculture development [1-4]. As a natural phenomenon of environmental water deficit at basin or regional scale, water shortage can evolve into a drought hazard when it lasts for a long time (such as a few months, even a year or several years), while short term environmental water surplus will lead to the occurrence of severe flood hazard. During the past half century, results from many studies have indicated that the frequency and severity of extreme climate events are increasing, causing more and more drought and flood hazards (e.g., [5, 6]). Furthermore, public awareness of extreme climatic events has risen sharply due to the catastrophic nature of floods, droughts, storms, and other climatic extremes [7]. Investigation of the changing characteristics of environmental dry/wet condition is important for water resource management and drought/flood prevention according to hydrological alterations $[7,8]$.

The status of environmental water deficit is the precondition for the occurrence of local flood or drought hazards. Up to now, people have developed various drought indices for environmental dry/wet estimation. Among which, the most widely used indices include the Palmer drought severity index (PDSI) [9-11] and the standardized precipitation index (SPI) [12-14] or normalised precipitation index (NPI) [15]. 
These indices are the typical indicators for assessing the conditions of meteorological dryness [16]. PDSI is an indicator of hydrometeorological dryness which is calculated from a simple water-balance model forced by monthly precipitation and temperature data [9]. However, lack of the multiscalar character and complex calculation processes makes the application of PDSI limited. The SPI and NPI calculation is based only on precipitation deficiency and does not consider other critical variables that may affect drought condition. Due to its robustness and convenience in application, SPI has already been widely used to characterize dry/wet conditions all over the world [17-19]. Moreover, it was recommended for meteorological dryness estimation in a recent meeting of the World Meteorological Organization (WMO) [20]. However, under the background of global change, increased temperature has become an important factor that has remarkable influence on drought process [21]. Thus, objective estimation of dry/wet conditions needs a comprehensive consideration of precipitation and temperature changes. Similar to the principle of SPI, Vicente-Serrano et al. [22] proposed a new drought index: standardized precipitation-evapotranspiration index (SPEI) by considering the effect of precipitation and temperature variability on meteorological dry/wet conditions. The index effectively integrates the sensitivity of evaporative demand of the PDSI and the multiscalar character of the SPI $[22,23]$, which is an ideal tool for dry/wet monitoring under the background of global warming.

The Poyang Lake catchment is one of the most sensitive regions of climate change in the Yangtze River basin [24]; studies on the changing properties of local climate and streamflow of the catchment have drawn increasing concerns in recent years. For example, Min and Liu [25] evaluated the change characteristics and possible underlying causes of extreme precipitation of the catchment. Tao et al. [26] investigated the spatial and temporal variability of temperature extreme indices for the period 1959-2010 and discussed the possible correlation with Global-SST ENSO index. Ye et al. [27] distinguished the relative impacts of climate change and human activities on the variation of catchment streamflow. In addition, several studies examined the variation of dry/wet condition of the catchment. Min et al. [28] analyzed the climatic characteristics of the drought in the Poyang Lake catchment by using the $Z$ index method. Li et al. [29] evaluated and compared the TRMM rainfall data with rain gauges data in Poyang Lake basin and investigated the usefulness of TRMM rainfall for monitoring the temporal and spatial distribution of dry/wet conditions by the SPI and $Z$ index method. However, to our knowledge, although quite a number of studies on this topic are available in the literatures, there is a lack of studies that rationally consider the effect of temperature variability on the change of meteorological dry/wet conditions under the background of global warming. Furthermore, evaluation of the impact of multitimescale variability of dry/wet conditions is very limited when addressing the occurrence of major drought and flood events in the lake inflow catchment in recent years.

As reported by many studies that annual precipitation and temperature in the Poyang Lake catchment are likely to increase continuously in the future as the results of global warming (e.g., [30, 31]), understanding spatial and temporal variability of dry/wet conditions of the lake inflow catchment is essential for the mitigation and prevention against the risk of natural hazards. Extending from previous studies, objectives of this study are as follows: (1) to investigate the characteristics of spatial and temporal variability of dry/wet conditions defined by SPEI, (2) to examine the evolution of SPEI at different timescales, and (3) to evaluate the impact of temperature variability on dry/wet conditions in recent years under the background of global warming.

\section{Study Region and Data}

The Poyang Lake catchment, located in the middle reach of the Yangtze River (Figure 1), serves as important water resource and ecological function in China. The catchment is mainly comprised of the five subcatchments: Ganjiang River, Fuhe River, Xinjiang River, Xiushui River, and Raohe River catchments (see Figure 1). The Poyang Lake at the outlet of the catchment receives water mainly from the five tributaries and discharges into the Yangtze River from a narrow watercourse in the north. The catchment area is about $162,200 \mathrm{~km}^{2}$, which accounts for 9\% of Yangtze River Basin and nearly $97 \%$ of Jiangxi Province. The catchment belongs to a subtropical climate with average annual temperature of $17.5^{\circ} \mathrm{C}$ and average annual precipitation of $1665 \mathrm{~mm}$. Due to the dominant effect of Southeast Asian Monsoon, forty-five percent of annual precipitation is concentrated in the wet season from April to June (Figure 1(b)).

Average annual discharge from the catchment is about $1450 \times 10^{8} \mathrm{~m}^{3}$, accounting for $15 \%$ of water resources of the whole Yangtze River basin. However, due to the uneven distribution of seasonal precipitation, the Poyang Lake catchment is one of the flood and drought-prone regions in China. During the past decades, both droughts and floods have occurred frequently in the lake, causing huge damage to the environment and the agricultural development. For example, the severe winter droughts of the catchment occurring in 2003-2004, 2006-2007, and 2008-2009 almost brought the lake water storage down to less than $1 \%$ of its capacity, which has raised wide concerns for the lake wetland ecology and local water resources management [32-34]. As a typical open water-carrying lake that naturally connects to the Yangtze River, the occurrence of droughts and floods in the lake is not only controlled by the Yangtze River discharge but also highly affected by the catchment inflow $[34,35]$. Therefore, changes of meteorological dry/wet conditions of the lake inflow catchment are particularly important for the occurrence of serious droughts and floods in the regional lake as well as the lower Yangtze River.

In this study, complete data set of daily precipitation and temperature from 14 standard national weather stations inside the catchment was obtained from National Climate Centre of China Meteorological Administration (CMA). Daily observations of all weather stations are available for the period of 1960-2010, and there is no missing data on the variables. Data quality control was made by CMA before delivery. Locations of these weather stations are indicated in Figure 1. 


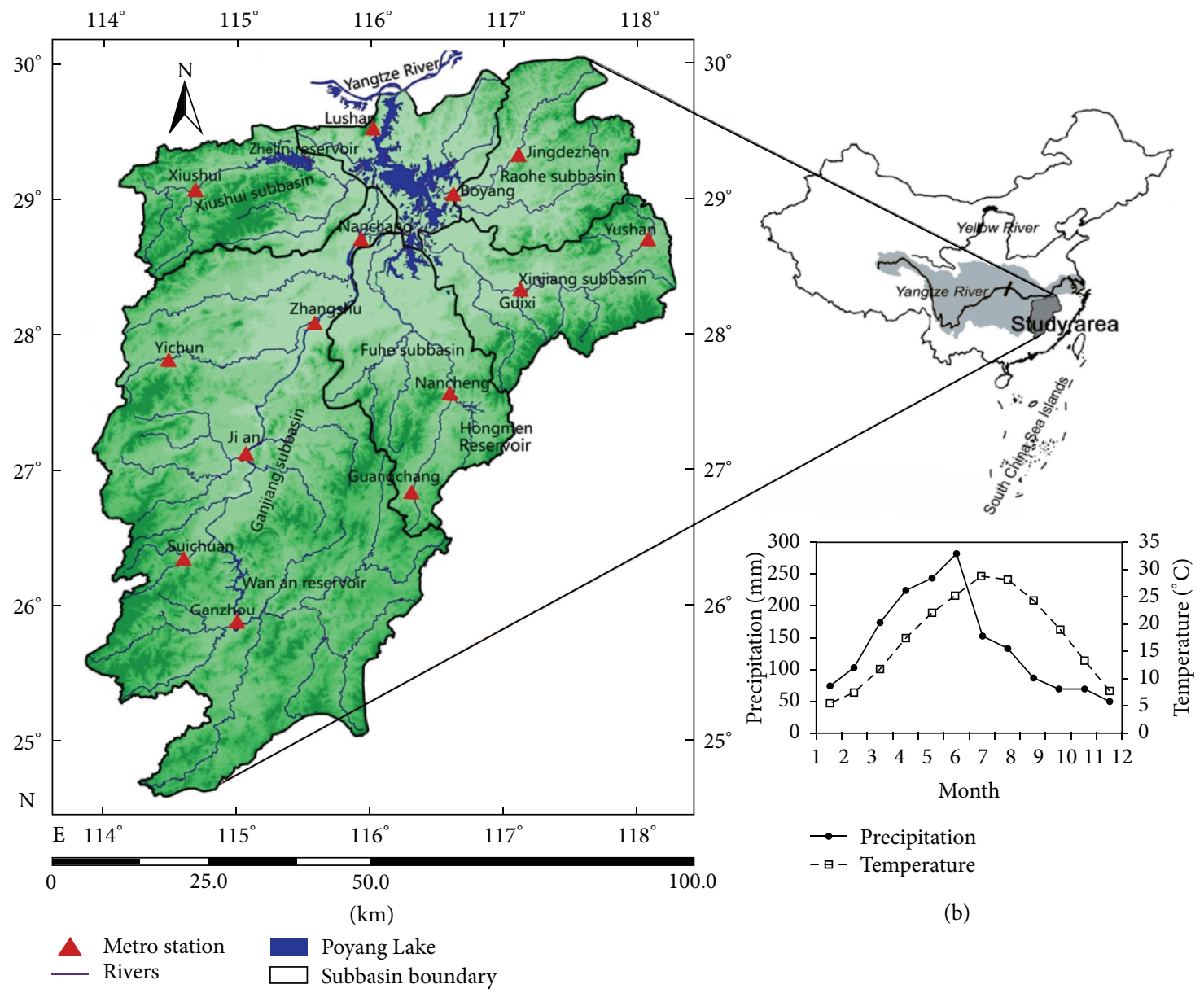

(a)

Figure 1: The geophysical location of Poyang Lake, China. (a) Distribution of meteorological stations across the Poyang Lake catchment, and (b) mean monthly precipitation and temperature of the Poyang Lake catchment for the period 1960-2010.

\section{Methodology}

3.1. Standardized Precipitation-Evapotranspiration Index (SPEI). The standardized precipitation-evapotranspiration index (SPEI) was proposed by Vicente-Serrano et al. [22] based on precipitation and potential evapotranspiration conditions. In contrast with other drought indices, SPEI combines the physical principles of the PDSI [12] with the multiscalar character of the SPI [9]. The calculation procedure of SPEI includes the following steps [22].

Step 1. Calculation of monthly climatic water balance:

$$
D_{i}=P_{i}-\mathrm{PET}_{i}
$$

where $P_{i}$ and $\mathrm{PET}_{i}$ are precipitation and potential evapotranspiration for the month $i$ and $D_{i}$ is the difference of the two variables. In this study, potential evapotranspiration was calculated by Thornthwaite method [36].
Step 2. Establishing the time series of water deficit at different timescales:

$$
D_{n}^{k}=\sum_{i=0}^{k-1}\left(P_{n-i}-\mathrm{PET}_{n-i}\right), \quad n \geq k
$$

where $k$ is timescale (month) and $n$ is computing times.

Step 3. Fitting the established data series by applying the probability density function of a three-parameter log-logistic distribution:

$$
f(x)=\frac{\beta}{\alpha}\left(\frac{x-\gamma}{\alpha}\right)^{\beta-1}\left[1+\left(\frac{x-\gamma}{\alpha}\right)^{\beta}\right]^{-2},
$$

where $\alpha, \beta$, and $\gamma$ are scale, shape, and origin parameters, respectively, which can be obtained by the L-moment 
TABLE 1: SPEI classification and corresponding probabilities of occurrence.

\begin{tabular}{lcc}
\hline Category & SPEI & Probability (\%) \\
\hline Extreme wet & SPEI $\geqslant 2.0$ & 2.3 \\
Severe wet & $1.5 \leqslant$ SPEI $<2.0$ & 4.4 \\
Moderate wet & $1.0 \leqslant$ SPEI $<1.5$ & 9.2 \\
Normal & $-1.0<$ SPEI $<1.0$ & 68.2 \\
Moderate dry & $-1.5<$ SPEI $\leqslant-1.0$ & 9.2 \\
Severe dry & $-2.0<$ SPEI $\leqslant-1.5$ & 4.4 \\
Extreme dry & SPEI $\leqslant-2.0$ & 2.3 \\
\hline
\end{tabular}

method. The cumulative probability at a given timescale is calculated as

$$
F(x)=\int_{0}^{x} f(x) d t=\left[1+\left(\frac{\alpha}{x-\gamma}\right)^{\beta}\right]^{-1} .
$$

Step 4. Transforming the data series of the cumulative probability to standard normal distribution, and then the SPEI can be calculated as follows:

$$
\begin{aligned}
\text { SPEI } & =W-\frac{C_{0}+C_{1}+C_{2} W^{2}}{1+d_{1} W+d_{2} W^{2}+d_{3} W^{3}}, \\
W & =\sqrt{-2 \ln (P)} \quad P \leq 0.5,
\end{aligned}
$$

where $P=1-F(x)$. When $P>0.5$, then $P$ is replaced by $1-P$. The constants are $C_{0}=2.515517, C_{1}=0.802853, C_{2}=$ $0.010328, d_{1}=1.432788, d_{2}=0.189269$, and $d_{3}=0.001308$.

According to the value of SPEI, meteorological dry/wet conditions can be classified into seven categories [22]. Table 1 lists the SPEI classification and corresponding cumulative probabilities of occurrences.

3.2. Standardized Precipitation Index (SPI). The standardized precipitation index (SPI) was proposed to quantify precipitation anomaly with respect to long-term normal conditions for multiple timescales [12]. It is one of the most widely used indicators for meteorological drought estimation. Generally, the calculation process of SPI is totally consistent with SPEI, but it just considers the precipitation deficiency on meteorological drought. In addition, both indexes have the same classification of the intensity of dry/wet conditions $[12,22,23,37]$. In this study, SPI was used as a reference index to evaluate the impact of temperature variability on dry/wet conditions within the context of global warming. More detailed information on the calculation of the SPI can be referred to the publications such as Mckee et al. [12] and Du et al. [37].

3.3. Trend Test. There are a lot of statistical techniques for trend test of data series, such as moving average, linear regression, and Mann-Kendall trend test. Although each method has its own strengths and weaknesses in trend detection, the nonparametric Mann-Kendall (MK) statistical test [38, 39] was applied in this study to estimate the change trends of seasonal SPEI due to its robustness against nonnormal distributions and insensitiveness to outliers. The test is widely used for trends detection in hydrological and climatological series (e.g., [27, 34]). According to the method, the null hypothesis $H_{0}$ of the test is that there is no trend of the calculated drought/wetness conditions from which the data set $X\left(x_{1}, x_{2}, x_{3}, \ldots, x_{n}\right)$ is drawn. The alternative hypothesis $H_{1}$ is that a monotonic trend exists in $X\left(x_{1}, x_{2}, x_{3}, \ldots, x_{n}\right)$. The null hypothesis $H_{0}$ should be rejected if $|Z| \geqslant 1.96$ at $5 \%$ significance level. The $Z$ value is a standard normal variable that represents the significance level of a specific trend. A positive value of $Z$ indicates increasing trend, and a negative value of $Z$ indicates decreasing trend.

\section{Results and Discussion}

4.1. Frequency of Dry and Wet Months of the Catchment. Based on the spatial averages of the meteorological data from all the stations, SPEI of the whole catchment was first estimated, and then cumulative frequency of dry and wet months of different category was calculated for the period 1960-2010. As shown in Figure 2, statistical results indicate there were 105 dry months occurring in the Poyang Lake catchment during the past 51 years, among which moderate dry episode occurred in 70 months, severe dry episode occurred in 27 months, and extreme dry episode occurred in 8 months. On seasonal basis, different category of dry episode can occur in any month of a year, and average occurrence of dry episode in each month is about 9 times. For each month, dry episode is most likely to occur in February, September, and November, while it is least likely to occur in March and June (Figure 2(a)). Moderate dry episode mainly occurred in September and November, severe dry episode in March and October, and extreme dry episode in May and June. As for the occurrence of wet episode of the catchment, there were totally 103 wet months that can be identified during the study period, among which moderate wet episode occurred in 57 months, severe wet episode in 35 months, and extreme wet episode in 11 months. The most frequent occurrence of wet episode is in November, December, and February, while the least is in January, March, and August (Figure 2(b)). Moderate wet episode mainly occurred in November and December, severe wet episode in December and February, and extreme wet episode in January and June.

Figure 3 further shows the cumulative frequency of dry and wet episodes of different categories under different periods. It can be seen that the occurrence of dry episodes in 1970s and 2000s was relatively frequent, and the most frequent occurrence for wet episodes was in 1970s and 1990s. Figure 3(a) indicates that extreme dry episodes mainly occurred in 1960s, 1990s, and 2000s and moderate dry episode and severe dry episode were relative frequent in 1970s and 2000s. In contrast, Figure 3(b) indicates that severe wet episodes and extreme wet episodes mainly occurred in 1990s; moderate wet episodes were frequent in 1970s, 1980s, and 2000s.

Generally, the above analysis indicates that the seasonal occurrence of meteorological dry or wet episodes in the 


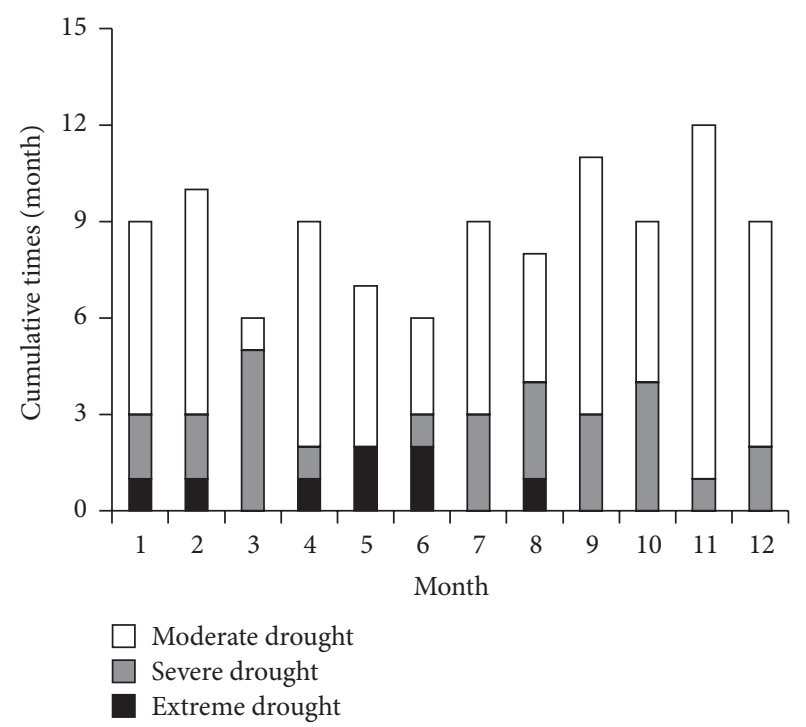

(a)

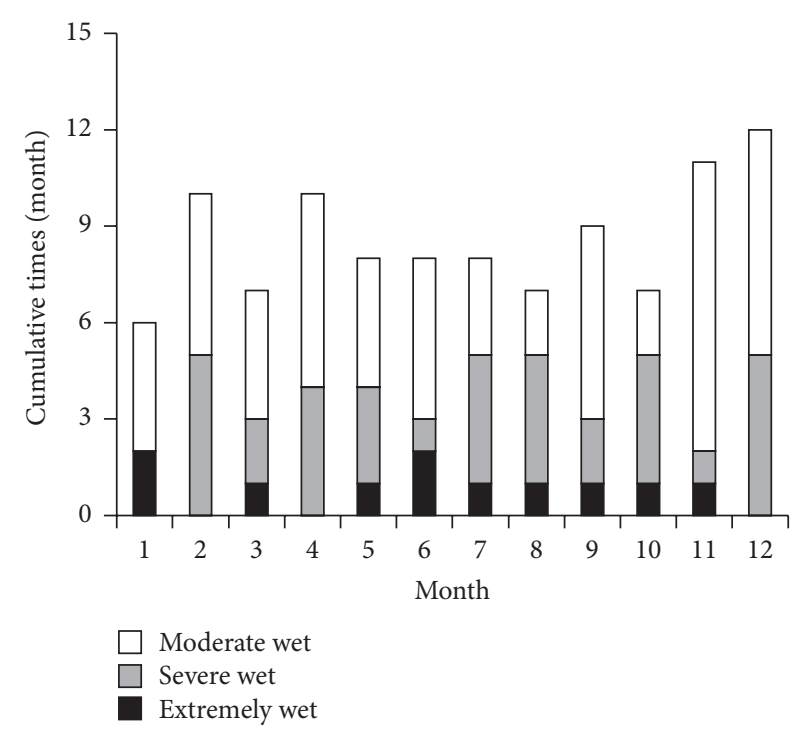

(b)

FIgURE 2: Monthly cumulative times of (a) dry and (b) wet episodes of different categories occurring in the Poyang Lake basin for the period 1960-2010.

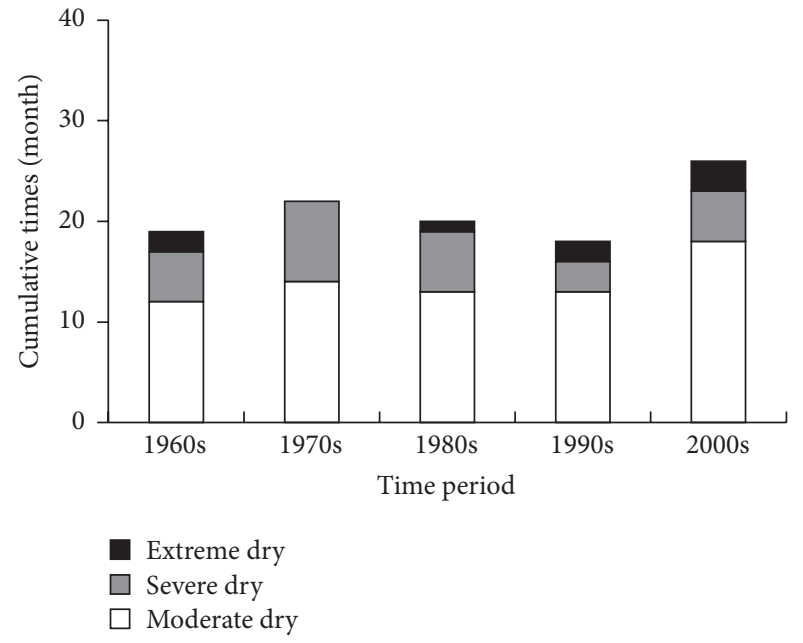

(a)

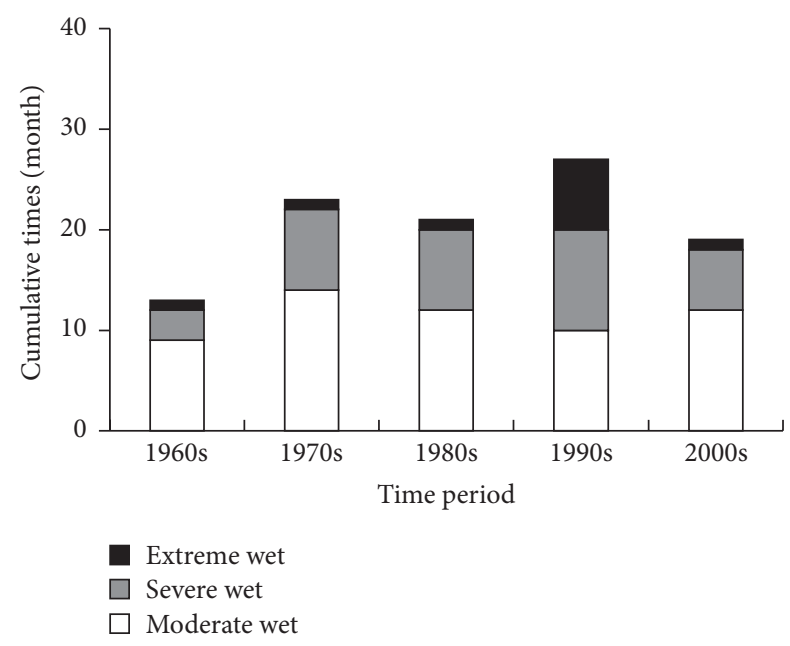

(b)

FIGURE 3: Cumulative times of (a) dry and (b) wet episodes of different categories occurring in the Poyang Lake basin under different periods.

Poyang Lake catchment is rather complex; different categories of dry and wet episodes may have occurred in most months of a year. During the study period, the occurrence of meteorological dry/wet episodes has become increasingly frequent in the recent two decades, especially the extreme wet episodes in 1990s and the extreme dry episodes in 2000s, which was consistent with the frequent flood and drought events occurring in the lake in recent years [32, 40, 41]. Although the occurrence of meteorological dry and wet episodes in the lake catchment does not mean the occurrence of droughts and floods in the lake, this result may indicate the consistence of climate anomaly in the Yangtze River basin and the importance of catchment inflow to the lake water variation.
4.2. Spatiotemporal Trends of Seasonal SPEI. To further study the temporal variability of dry and wet episodes in the catchment, MK test was applied to analyze the trends for SPEI of each season. The estimation of seasonal SPEI was done through calculating a 3-month timescale SPEI at February, May, August, and November for winter, spring, summer, and autumn, respectively. According to the principle of SPEI, the 3 -month SPEI at month $t$ was calculated using precipitation and evapotranspiration data at months $t-2, t-1$, and $t$ [22].

According to trend analysis of the 14 standard national weather stations inside the catchment, spatial distribution of seasonal SPEI trends was obtained by using a simple linear interpolation method (Figure 4). Positive and negative $Z$ values in Figure 4 represent trends toward wetter and drier 


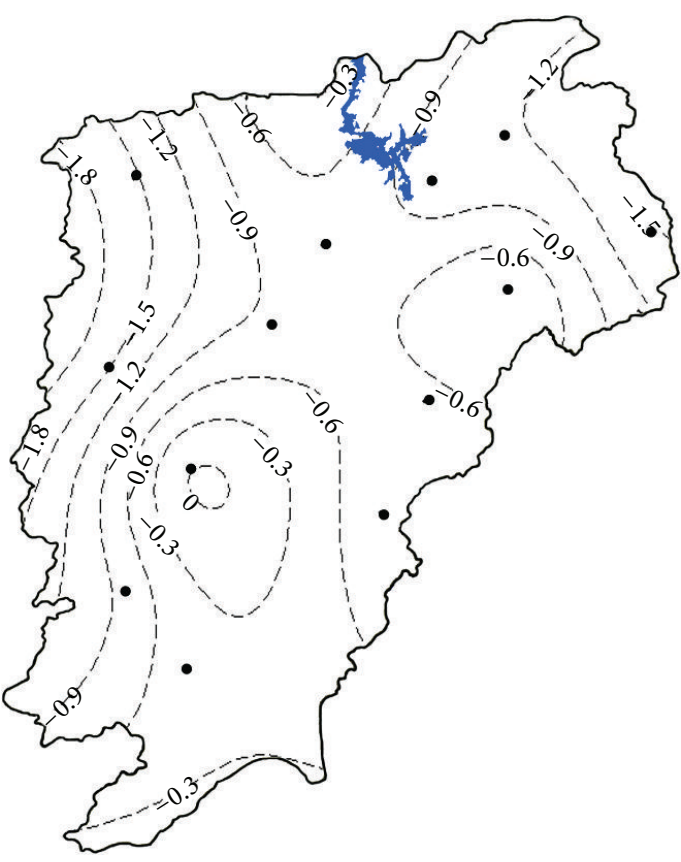

(a) Spring

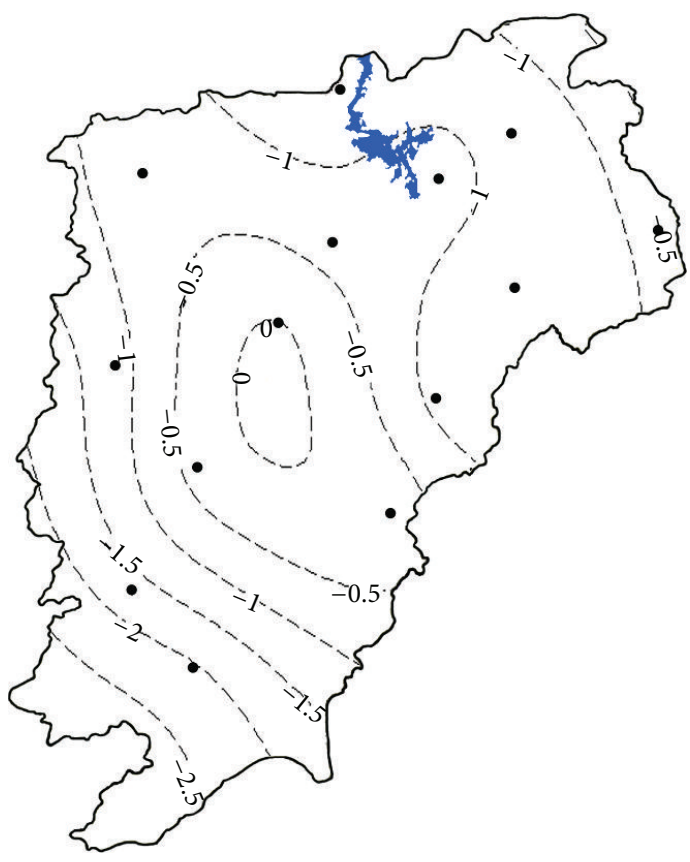

(c) Autumn

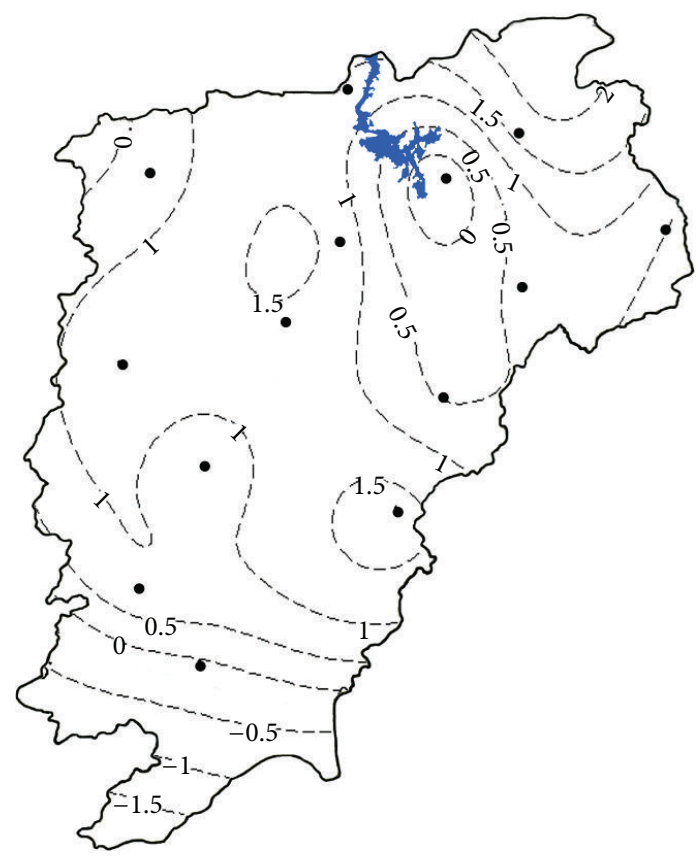

(b) Summer

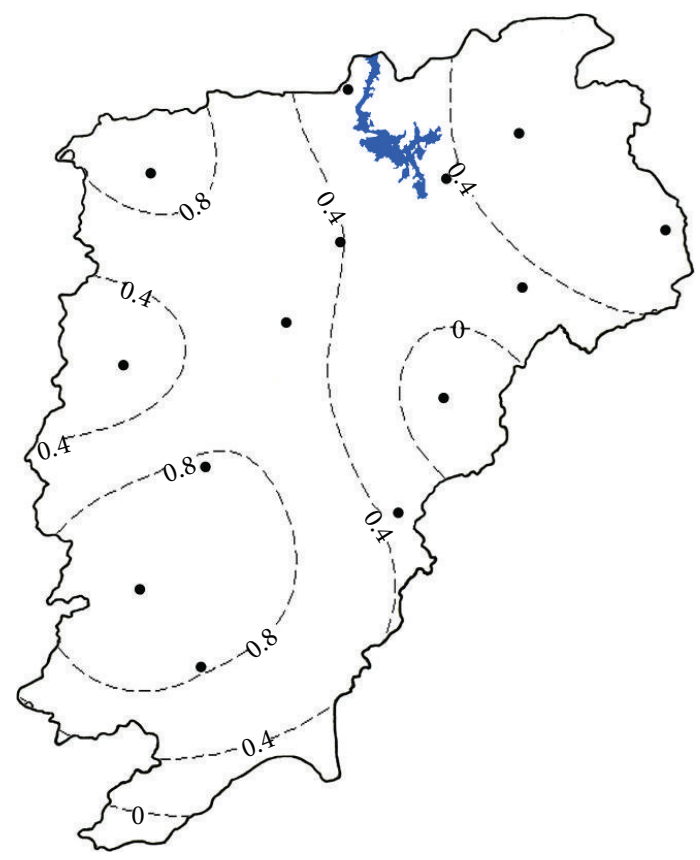

(d) Winter

FIGURE 4: Spatial distribution pattern of trends of SPEI in (a) spring (March, April, and May), (b) summer (June, July, and August), (c) autumn (September, October, and November), and (d) winter (January, February, and December) across the Poyang Lake basin. The numbers in the figure are $Z$ values of MK test. Positive values indicate increasing trend and vice versa. If $|Z| \geqslant 1.96$, then the trend is significant at $>95 \%$ confidence level.

conditions, respectively. It can be seen that the temporal variability of dry and wet episodes in the catchment shows somewhat seasonal characteristics. The whole catchment was almost characterized by decreasing SPEI trends in spring (Figure 4(a)) and increasing SPEI trends in summer (Figure 4(b)), indicating that a drying tendency dominates the Poyang Lake catchment in spring and a wet tendency prevails in summer. Although the decreasing trends are not significant at 95\% confidence level in the spring season, the drying tendencies in the northwest and northeast parts of the catchment are relatively severe. Also, the summer wet tendencies in northeast and central parts of the catchment 
TABLE 2: Statistical results of frequency and average duration of dry and wet episodes according to different timescales of SPEI.

\begin{tabular}{|c|c|c|c|c|c|c|}
\hline Dry/wet & SPEI-1 & SPEI-3 & SPEI-6 & SPEI-12 & SPEI-24 & SPEI-48 \\
\hline \multicolumn{7}{|l|}{ Dry } \\
\hline Frequency (times) & 71 & 39 & 20 & 7 & 7 & 4 \\
\hline Average duration (months) & 1.48 & 2.33 & 4.85 & 14.71 & 14.00 & 24.75 \\
\hline \multicolumn{7}{|l|}{ Wet } \\
\hline Frequency (times) & 67 & 35 & 19 & 10 & 6 & 2 \\
\hline Average duration (months) & 1.54 & 3.20 & 5.89 & 10.60 & 17.00 & 53.00 \\
\hline
\end{tabular}

are relatively severe and not significant. These trends can also be identified in autumn and winter. Figure 4(c) shows that the entire Poyang Lake catchment, except for a small part in the central region, is characterized by decreasing SPEI trends in the autumn, indicating a drying tendency of this season. The drying tendency is particularly significant in the southwest part of the catchment with SPEI trends significant at the $95 \%$ confidence level. Figure 4(d) shows that the entire Poyang Lake catchment is characterized by increasing SPEI in winter. Thus, the wet tendency prevails over the catchment in the winter season, although the increasing trends are not significant at $95 \%$ confidence level.

4.3. Variability of Multitimescales of SPEI. According to the definition described by McKee et al. [12], the frequency and duration of dry and wet episodes at different timescales were calculated. In the definition, the beginning of a dry episode that is defined as SPEI (or SPI) continued to be negative and reached -1.0 , and the end of the episode that is defined as SPEI (or SPI) turned out to be positive, and vice versa for wet event. Table 2 lists the statistical results of frequency and average duration of dry and wet episodes according to different timescales of SPEI. Generally, during the study period, the frequency of dry episodes is larger than that of the wet episodes, except for SPEI-12, while the average duration of wet episodes is longer. The average duration of SPEI-3 dry episodes is 2.33 months and for wet episodes it is 3.20 months. However, average duration of SPEI-48 dry episodes is 24.75 months, which is much shorter than the average duration of 53.00 months of wet episodes, and the longest can last for 8 years (1995-2003).

Figure 5 shows the evolution of multitimescales of SPEI values of the Poyang Lake catchment during 1960-2010. Because the shorter timescale of SPEI is sensitive to precipitation and temperature, the estimated 1-month SPEI (SPEI-1) and 3-month SPEI (SPEI-3) in Figure 5 are characterized by seasonal oscillations with large fluctuation during the study period. The occurrence of those dry or wet episodes that last for half a year is also frequent and shows interannual oscillations (such as SPEI-6 in Figure 5). In addition, variability of SPEI-24 and SPEI-48 presents a feature of interdecadal variability. Consistently, on decadal scale, continued and consecutive dry or wet episodes that last for several years usually occurred in the Poyang Lake catchment, such as 1963-1966 dry episode, 1978-1979 dry episode, 1993-1999 wet episode, and 2006-2009 dry episode. The consecutive wet episodes in 1993-1999 caused frequent flood hazards in the catchment; for instance, the maximum catchment discharge to Poyang Lake in 1998 was about $7 \times 10^{4} \mathrm{~m}^{3} / \mathrm{s}$, the maximum in the recent 50 years [40]. However, the consecutive dry episodes in 2006-2009 led to a severe water deficit of the catchment [41], causing sharp decline of groundwater level and reservoir water level and water supply and irrigation problems for millions of inhabitants in the catchment [34]. Thus, the multitimescales of SPEI can clearly reflect the status of available water resources under the evolution of meteorological dry/wet conditions. As discussed by other papers (e.g., $[12,42])$, variations of SPEI-1 and SPEI-3 are mainly affected by monthly precipitation and temperature and can be used to estimate the condition of upper soil moisture. Variations of SPEI-6 and SPEI-12 well reflect the condition of lower soil moisture and the river runoff, while SPEI-24 and SPEI48 may indicate the condition of groundwater resources and reservoir storage.

Because the SPEI curves of different timescales are different in periodicity, amplitude, and initial phase, the dry and wet episodes at different timescales may happen simultaneously and consequently produce extreme drought or flood events [43]. Figure 5 shows that SPEI-48 reached the minimum values in $1966(-1.86)$ and $2009(-1.80)$. It takes 4 years for SPEI-48 to return to normal climate condition after 1966. When in consideration of short-timescale SPEI variation (such as SPEI-3), it is clear that different timescales of dry episodes are easy to encounter and their effects can be overlapped. This is also applicable to the wet episodes. Taking 1992, 2007, and 2009 as examples of drought events in the catchment, the SPEI for these three years are obviously negative for timescales less than 6 months. However, the intensity of the drought event occurred in 1992 and its influence is much smaller than the droughts in 2007 and 2009. It has been reported that lots of rivers as well as reservoirs almost dried out in 2007 and 2009; furthermore, shallow groundwater wells used as the major water supply for many of the villages in the catchment failed to meet demand due to the decline of groundwater levels [34]. The severe drought events in 2007 and 2009 occurred based on the background that shorter timescales of dry episodes and the longer timescales of dry episodes (SPEI-24 and SPEI-48) were encountered and overlapped. This result indicates that a large part of precipitation in 2007 and 2009 was required to compensate the accumulated water deficit of groundwater and reservoirs in the catchment and therefore aggravated the severity and influence of these droughts. On the contrary, the occurrence of 1998 flood, the severest flood hazard in 

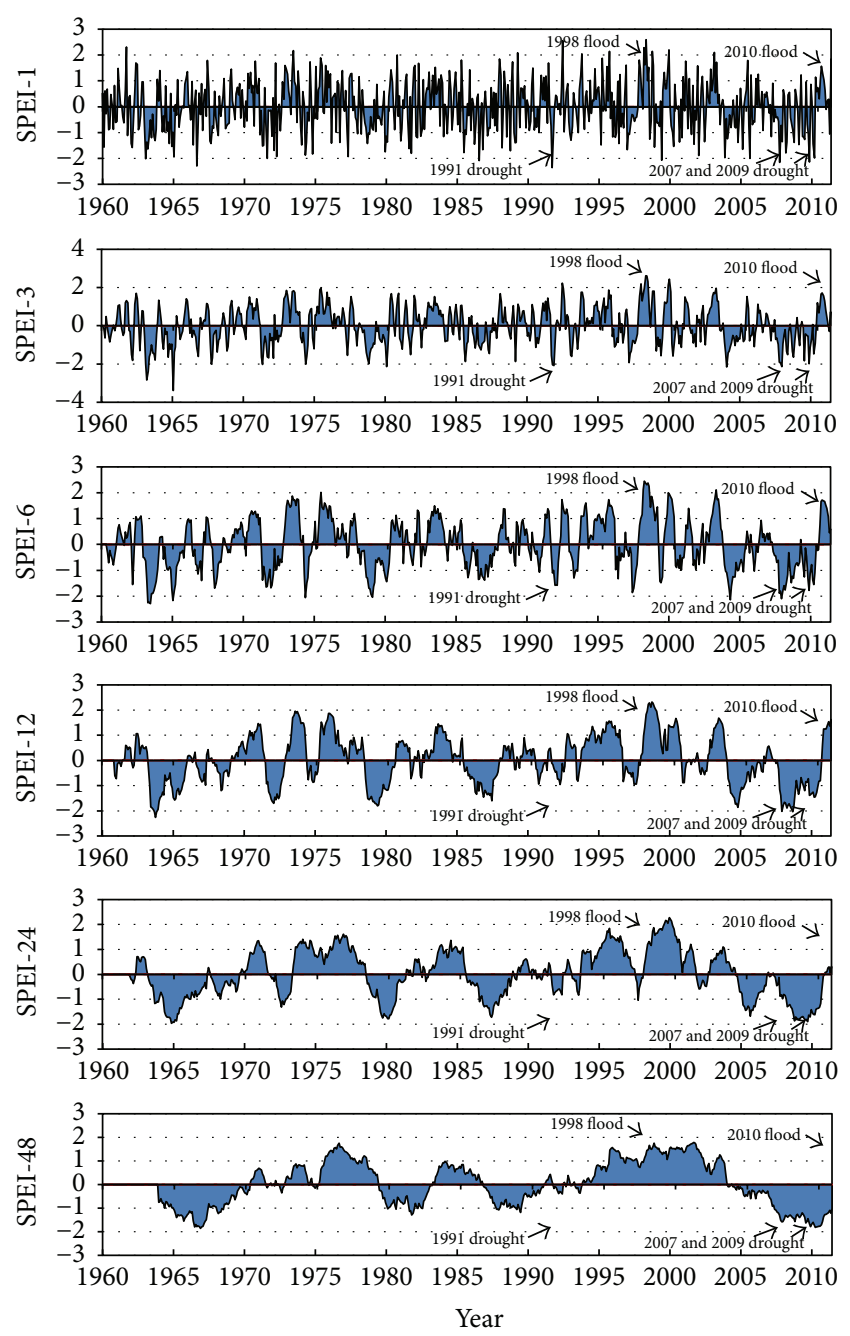

FIGURE 5: Evolution of multitimescale of SPEI values and major drought/flood events in the Poyang Lake catchment during 19602010.

recent 50 years, exactly coincided with the encounter and overlap of multitimescale wet episodes since the positive SPEI is particularly obvious at all timescales (Figure 5). However, different from the 1998 flood, longer timescales of SPEI (SPEI-24 and SPEI-48) of another flood in 2010 show normal or dry conditions, which were conducive to alleviate the flood intensity.

\subsection{Impact of Temperature Changes on Dry/Wet Variability} in Recent Years. Temperature has an important effect on the intensity, scope, and duration of dry/wet condition. Its impact on meteorological dry/wet condition is mainly realized by affecting the rate of evaporation. When temperature increases, the evaporation rate will be accelerated, and this will aggravate the severity of drought, and vice versa [44]. Because the process of SPEI estimation is completely consistent with SPI but just adds the effect of potential evapotranspiration, the differences between SPEI and SPI
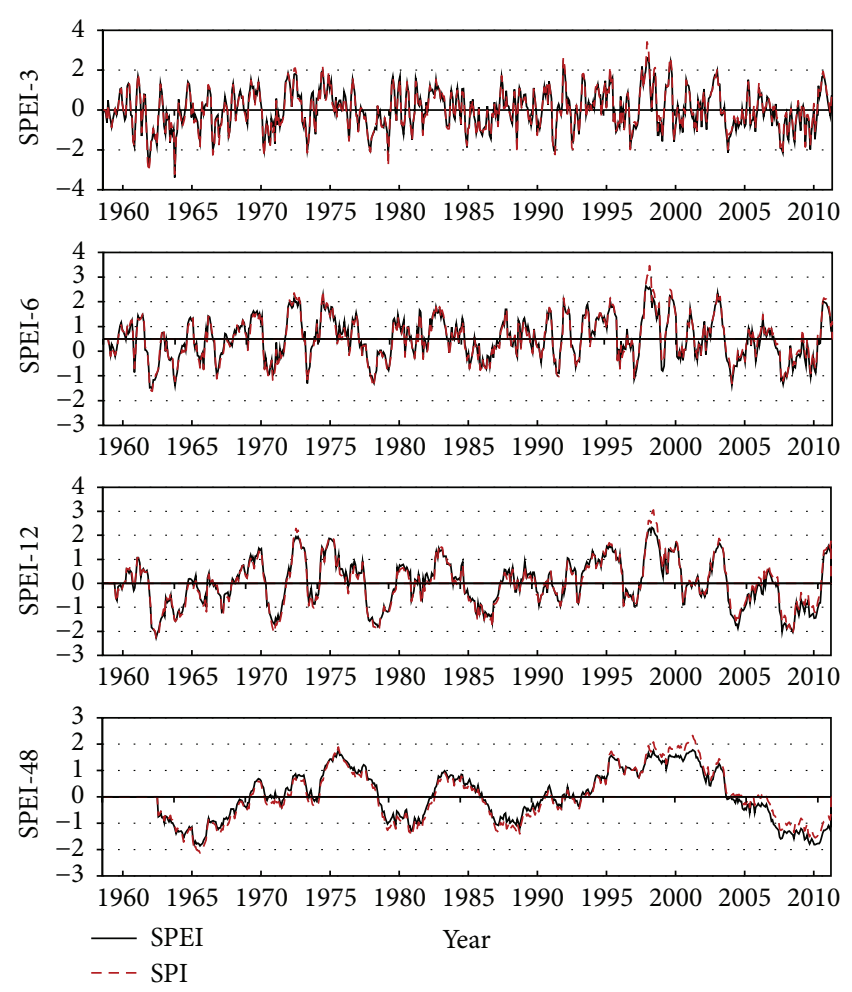

(a)

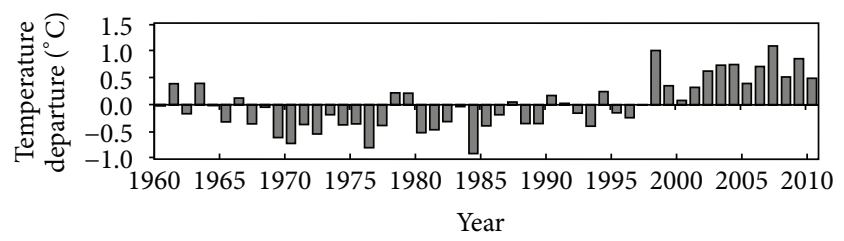

(b)

FIgURE 6: (a) Comparison of multitimescales of SPEI and SPI during 1960-2010; (b) variation of annual temperature departures during 1960-2010.

reflect the contribution of temperature variability on the intensity of dry/wet condition.

As an example, Figure 6(a) shows the comparison of SPEI and SPI variations at timescales of $3,6,12$, and 48 months during the study period. We can see that the fluctuations of SPEI and SPI show highly consistent patterns, with small discrepancy at certain times. With timescales increasing, the discrepancy between SPEI and SPI became more and more obvious. The SPEI curve is obviously higher than SPI curve during 1965-1986 but lower than SPI curve during 1998-2010 under the timescale of 48 months. In consideration of the impact of temperature changes on dry/wet conditions during the study period, it can be concluded that the higher SPEI curve during 1965-1986 indicates a reduced dry intensity, while the lower SPEI curve during 1998-2010 indicates an increased dry intensity. During the period of 1986-1995, the impact of temperature is small, and also the SPEI curve shows almost coincidence with SPI curve. 
Precipitation deficit is considered to be the dominant factor that affects the intensity of dry/wet condition; however, temperature variability may play a modulating role. Figure 6(b) displays the anomaly of annual temperature of the Poyang Lake catchment in recent years, which indicates that the catchment has experienced a relative low temperature period in 1965-1986 and a quick increase period after 1998. It is clear that negative temperature departure during 19651986 can alleviate drought in the dry year with SPEI < SPI and intensify flood in the wet year with SPEI > SPI. Similarly, positive temperature departure during 1998-2010 can alleviate flood in the wet year with SPEI < SPI and intensify drought in the dry year with SPEI $>$ SPI. Statistical result indicates that the average annual temperature during the period $1998-2010$ is about $0.6^{\circ} \mathrm{C}$ higher than the longterm average, and maximum temperature anomaly in 2007 can reach up to $1.08^{\circ} \mathrm{C}$. On annual bases, for the typical drought years of 2003, 2007, and 2009, our observation indicates that the contribution of increased temperature to drought intensity of the catchment is about $22.8 \%, 9.1 \%$, and $23.9 \%$, respectively. Therefore, in addition to the effect of less precipitation, the increased temperature is another important factor for the severe and continued droughts in the Poyang Lake catchment after 2003.

\section{Conclusions}

By using the latest proposed drought index (SPEI), this paper quantitatively investigated the evolution characteristics of meteorological dry/wet variations in the Poyang Lake catchment, China, for the period of 1960-2010. The results demonstrate that the occurrence of meteorological dry or wet episodes in the Poyang Lake catchment is rather complex; different categories of dry and wet episodes can occur in most months of a year. The occurrence of meteorological dry and wet episodes has become increasingly frequent in the recent two decades, especially the extreme wet episodes in 1990s and the extreme dry episodes in 2000s. Different dry or wet tendencies can be identified in the Poyang Lake catchment under different seasons. Generally, drying tendency is found to be dominant over the lake catchment in spring and autumn, while wet tendency will prevail in summer and winter.

Because the different timescales of SPEI reflect the status of different available water resources, this paper concluded that the dry or wet episodes at different timescales may occur simultaneously and consequently produce extreme drought or flood events. Historically, the encounter and overlap of multitimescales of meteorological dry/wet episodes is an important background for several severe droughts and floods across the catchment.

In addition, this study revealed that the impact of temperature anomaly to the dry/wet variability may not be neglected. In the Poyang catchment, negative temperature departure during 1965-1986 can alleviate droughts in the dry years and intensify floods in the wet years. Similarly, positive temperature departure during 1998-2010 can alleviate floods in the wet years and intensify droughts in the dry years. It is anticipated that annual temperature will increase continuously in the future as a result of global warming; integrate consideration of the joint effects of precipitation and temperature changes is needed for the objective characterization of dry/wet conditions in those large lake catchments in humid climatic zone.

\section{Conflict of Interests}

The authors declare that there is no conflict of interests regarding the publication of this paper.

\section{Acknowledgments}

This work was financially supported by the National Basic Research Program of China (2012CB417003), the Collaborative Innovation Center for Major Ecological Security Issues of Jiangxi Province and Monitoring Implementation (JXS-EW-00), National Natural Science Foundation of China (41201026), and the Science Foundation of Nanjing Institute of Geography and Limnology, Chinese Academy of Sciences (NIGLAS2012135001).

\section{References}

[1] IPCC, Climate Change: Fourth Assessment Report of the Intergovernmental Panel on Climate Change, Cambridge University Press, Cambridge, UK, 2007.

[2] C.-Y. Xu, L. Gong, T. Jiang, D. Chen, and V. P. Singh, "Analysis of spatial distribution and temporal trend of reference evapotranspiration and pan evaporation in Changjiang (Yangtze River) catchment," Journal of Hydrology, vol. 327, no. 1-2, pp. 81-93, 2006.

[3] S. J. Déry, M. A. Hernández-Henríquez, J. E. Burford, and E. F. Wood, "Observational evidence of an intensifying hydrological cycle in northern Canada," Geophysical Research Letters, vol. 36, no. 13, Article ID L13402, 2009.

[4] J. R. Thompson, "Modelling the impacts of climate change on upland catchments in southwest Scotland using MIKE SHE and the UKCP09 probabilistic projections," Hydrology Research, vol. 43, no. 4, pp. 507-530, 2012.

[5] M. M. Q. Mirza, "Global warming and changes in the probability of occurrence of floods in Bangladesh and implications," Global Environmental Change, vol. 12, no. 2, pp. 127-138, 2002.

[6] B. C. Bates, Z. W. Kundzewicz, S. Wu, and J. P. Palutikof, "Climate change and water," Technical Paper of the Intergovernmental Panel on Climate Change, IPCC Secretariat, Geneva, Switzerland, 2008.

[7] Q. Zhang, C.-Y. Xu, and Z. X. Zhang, "Observed changes of drought/wetness episodes in the Pearl River basin, China, using the standardized precipitation index and aridity index," Theoretical and Applied Climatology, vol. 98, no. 1-2, pp. 89-99, 2009.

[8] C.-Y. Xu and V. P. Singh, "Review on regional water resources assessment models under stationary and changing climate," Water Resources Management, vol. 18, no. 6, pp. 591-612, 2004.

[9] W. C. Palmer, "Meteorological drought," Research Paper 45, US Weather Bureau, 1965. 
[10] J. Sheffield and E. F. Wood, "Global trends and variability in soil moisture and drought characteristics, 1950-2000, from observation driven simulations of the terrestrial hydrologic cycle," Journal of Climate, vol. 21, no. 3, pp. 432-458, 2008.

[11] J. Sheffield, E. F. Wood, and M. L. Roderick, "Little change in global drought over the past 60 years," Nature, vol. 491, no. 7424 , pp. 435-438, 2012.

[12] B. T. McKee, J. N. Doesken, and J. Kleist, "The relationship of drought frequency and duration to time scales," in Proceedings of the 8th Conference on Applied Climatology, pp. 179184, American Meteorological Society, Anaheim, Calif, USA, January 1993.

[13] O. Bothe, K. Fraedrich, and X. Zhu, "The large-scale circulations and summer drought and wetness on the Tibetan plateau," International Journal of Climatology, vol. 30, no. 6, pp. 844-855, 2010.

[14] S. N. Rahmat, N. Jayasuriya, and M. Bhuiyan, "Assessing droughts using meteorological drought indices in Victoria, Australia," Hydrology Research, vol. 46, no. 3, pp. 463-476, 2015.

[15] R. Gosling, "Assessing the impact of projected climate change on drought vulnerability in Scotland," Hydrology Research, vol. 45, no. 6, pp. 806-816, 2014.

[16] J. S. Wang, J. Y. Guo, Y. W. Zhou, and L. F. Yang, "Research progress and prospects of drought indicators," Arid Land Geography, vol. 30, pp. 60-65, 2007.

[17] H. Wu, M. D. Svoboda, M. J. Hayes, D. A. Wilhite, and F. Wen, "Appropriate application of the standardized precipitation index in arid locations and dry seasons," International Journal of Climatology, vol. 27, no. 1, pp. 65-79, 2007.

[18] L. Vergni and F. Todisco, "Spatio-temporal variability of precipitation, temperature and agricultural drought indices in central Italy," Agricultural and Forest Meteorology, vol. 151, no. 3, pp. 301-313, 2011.

[19] A. R. Nafarzadegan, M. Rezaeian Zadeh, M. Kherad et al., "Drought area monitoring during the past three decades in Fars province, Iran," Quaternary International, vol. 250, pp. 27-36, 2012.

[20] M. Hayes, M. Svoboda, N. Wall, and M. Widhalm, "The lincoln declaration on drought indices: universal meteorological drought index recommended," Bulletin of the American Meteorological Society, vol. 92, no. 4, pp. 485-488, 2011.

[21] A. G. Dai, "Drought under global warming: a review," Wiley Interdisciplinary Reviews: Climate Change, vol. 2, no. 1, pp. 4565, 2011.

[22] S. M. Vicente-Serrano, S. Beguería, and J. I. López-Moreno, "A multiscalar drought index sensitive to global warming: the standardized precipitation evapotranspiration index," Journal of Climate, vol. 23, no. 7, pp. 1696-1718, 2010.

[23] H. Tao, H. Borth, K. Fraedrich, B. D. Su, X. H. Zhu, and Y. G. Bai, "Drought and wetness variability in the Tarim River Basin and connection to large-scale atmospheric circulation," International Journal of Climatology, vol. 34, no. 8, pp. 26782684, 2014.

[24] H. Guo, B. Su, Y. Wang, and T. Jiang, "Runoff coefficients change and the analysis of the relationship between climate factors and runoff coefficients in Poyang Lake Basin (China):19552002," Journal of Lake Sciences, vol. 19, no. 2, pp. 163-169, 2007 (Chinese).

[25] S. Min and J. Liu, "Characteristics and causes of the extreme precipitation anomaly in Lake Poyang area," Journal of Lake Sciences, vol. 23, no. 3, pp. 435-444, 2011 (Chinese).
[26] H. Tao, K. Fraedrich, C. Menz, and J. Q. Zhai, "Trends in extreme temperature indices in the Poyang Lake Basin, China," Stochastic Environmental Research and Risk Assessment, vol. 28, no. 6, pp. 1543-1553, 2014.

[27] X. C. Ye, Q. Zhang, J. Liu, X. H. Li, and C.-Y. Xu, "Distinguishing the relative impacts of climate change and human activities on variation of stream flow in the Poyang Lake catchment, China," Journal of Hydrology, vol. 494, pp. 83-95, 2013.

[28] S. Min, M. Yan, and J. Liu, "Climatic characteristics of the drought in Lake Poyang catchment," Journal of Lake Sciences, vol. 25, no. 1, pp. 65-72, 2013 (Chinese).

[29] X. H. Li, Q. Zhang, and X. C. Ye, "Dry/wet conditions monitoring based on TRMM rainfall data and its reliability validation over Poyang Lake Basin, China," Water, vol. 5, no. 4, pp. 18481864, 2013.

[30] H. Guo, G. Q. Yin, and T. Jiang, "Prediction on the possible climate change of Poyang Lake basin in the future 50 years," Resources and Environment in the Yangtze Basin, vol. 17, pp. 7378, 2008 (Chinese).

[31] X. C. Ye, Q. Zhang, L. Bai, and Q. Hu, "A modeling study of catchment discharge to Poyang Lake under future climate in China," Quaternary International, vol. 244, no. 2, pp. 221-229, 2011.

[32] Q. Min and L. Zhan, "Characteristics of low-water level changes in Lake Poyang during 1952-2011," Journal of Lake Sciences, vol. 24, no. 5, pp. 675-678, 2012 (Chinese).

[33] L.-L. Zhang, J.-X. Yin, Y.-X. Jiang, and H. Wang, "Relationship between the hydrological conditions and the distribution of vegetation communities within the Poyang Lake National Nature Reserve, China," Ecological Informatics, vol. 11, pp. 6575, 2012.

[34] Q. Zhang, X.-C. Ye, A. D. Werner et al., "An investigation of enhanced recessions in Poyang Lake: comparison of Yangtze River and local catchment impacts," Journal of Hydrology, vol. 517, pp. 425-434, 2014.

[35] Q. Hu, S. Feng, H. Guo, G. Chen, and T. Jiang, "Interactions of the Yangtze river flow and hydrologic processes of the Poyang Lake, China," Journal of Hydrology, vol. 347, no. 1-2, pp. 90-100, 2007.

[36] C. W. Thomthwaite, "An approach toward a rational classification of climate," Geophysical Review, vol. 8, pp. 55-94, 1948.

[37] J. Du, J. Fang, W. Xu, and P. J. Shi, "Analysis of dry/wet conditions using the standardized precipitation index and its potential usefulness for drought/flood monitoring in Hunan Province, China," Stochastic Environmental Research and Risk Assessment, vol. 27, no. 2, pp. 377-387, 2013.

[38] H. B. Mann, "Nonparametric tests against trend," Econometrica, vol. 13, pp. 245-259, 1945.

[39] M. G. Kendall, Rank Correlation Methods, Griffin, London, UK, 1975.

[40] Q. Min, "Analysis on the flood characters in 1990s, Poyang Lake," Journal of Lake Sciences, vol. 14, no. 4, pp. 323-330, 2002 (Chinese).

[41] Y. B. Liu, G. P. Wu, and X. S. Zhao, "Recent declines in China's largest freshwater lake: trend or regime shift?" Environmental Research Letters, vol. 8, no. 1, Article ID 014010, 9 pages, 2013.

[42] H.X. Su and G. Q. Li, "Low-frequency drought variability based on SPEI in association with climate indices in Beijing," Acta Ecologica Sinica, vol. 32, no. 17, pp. 5467-5475, 2012 (Chinese). 
[43] L. Wang and W. Chen, "Characteristics of multi-times cale variabilities of the drought over last 100 years in Southwest China," Advances in Meteorological Science and Technology, vol. 2, pp. 21-26, 2012 (Chinese).

[44] X.-C. Ye, X.-H. Li, J. Liu, C.-Y. Xu, and Q. Zhang, "Variation of reference evapotranspiration and its contributing climatic factors in the Poyang Lake catchment, China," Hydrological Processes, vol. 28, no. 25, pp. 6151-6162, 2014. 

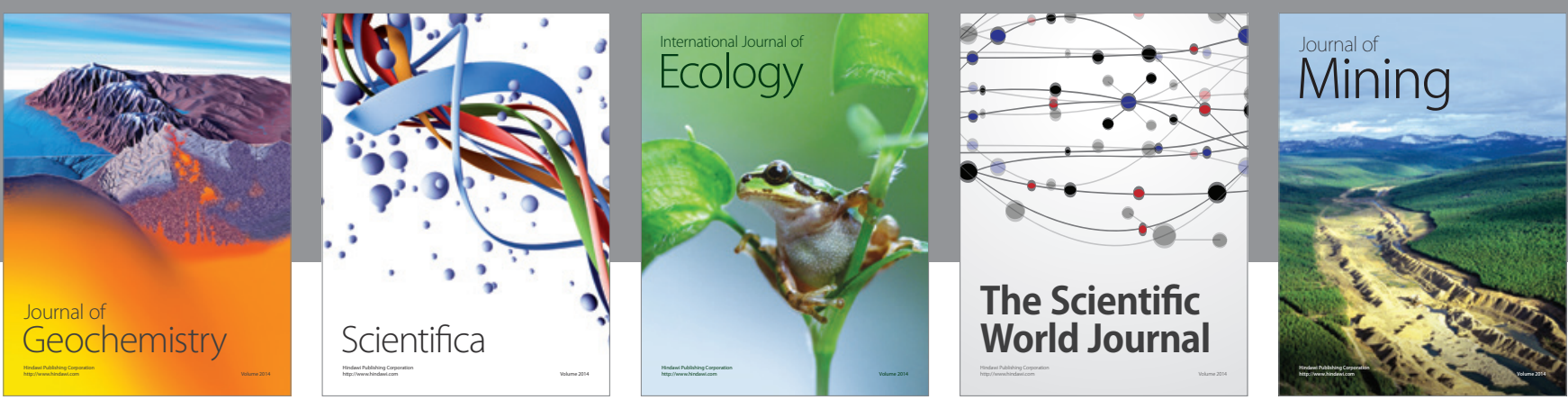

The Scientific World Journal
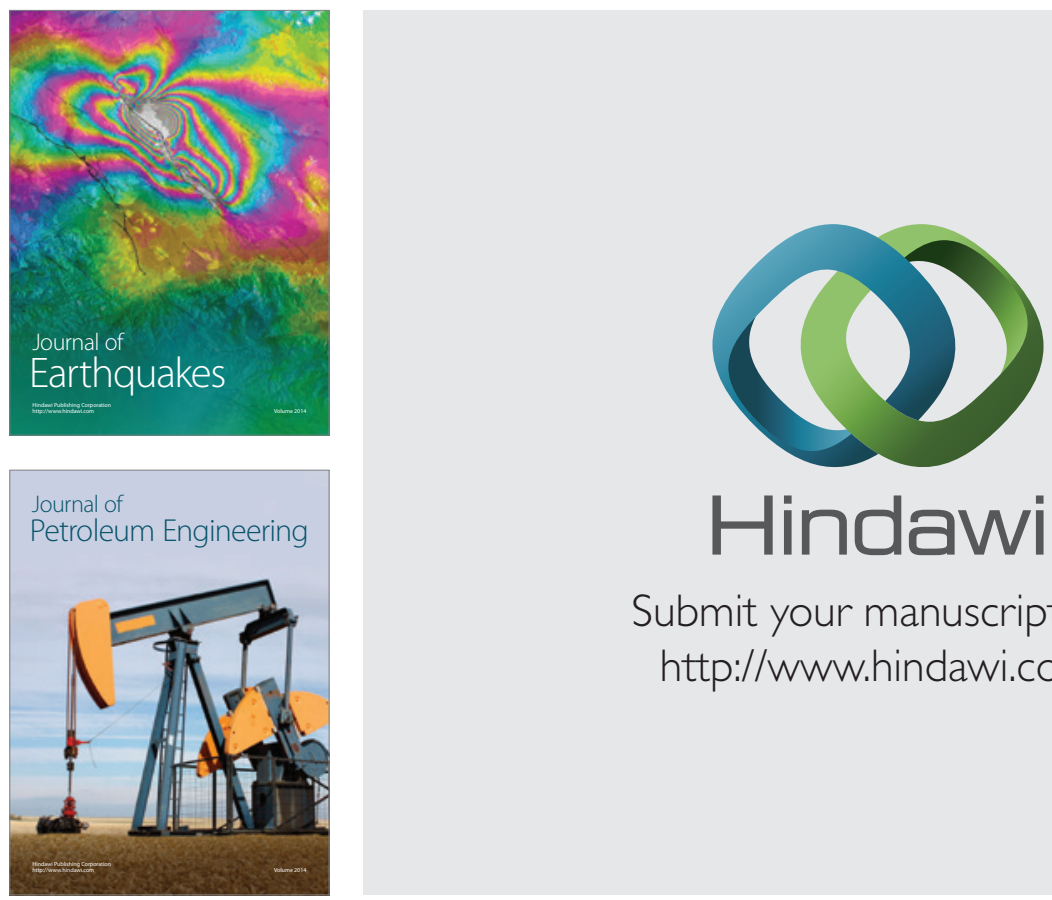

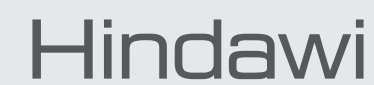

Submit your manuscripts at

http://www.hindawi.com
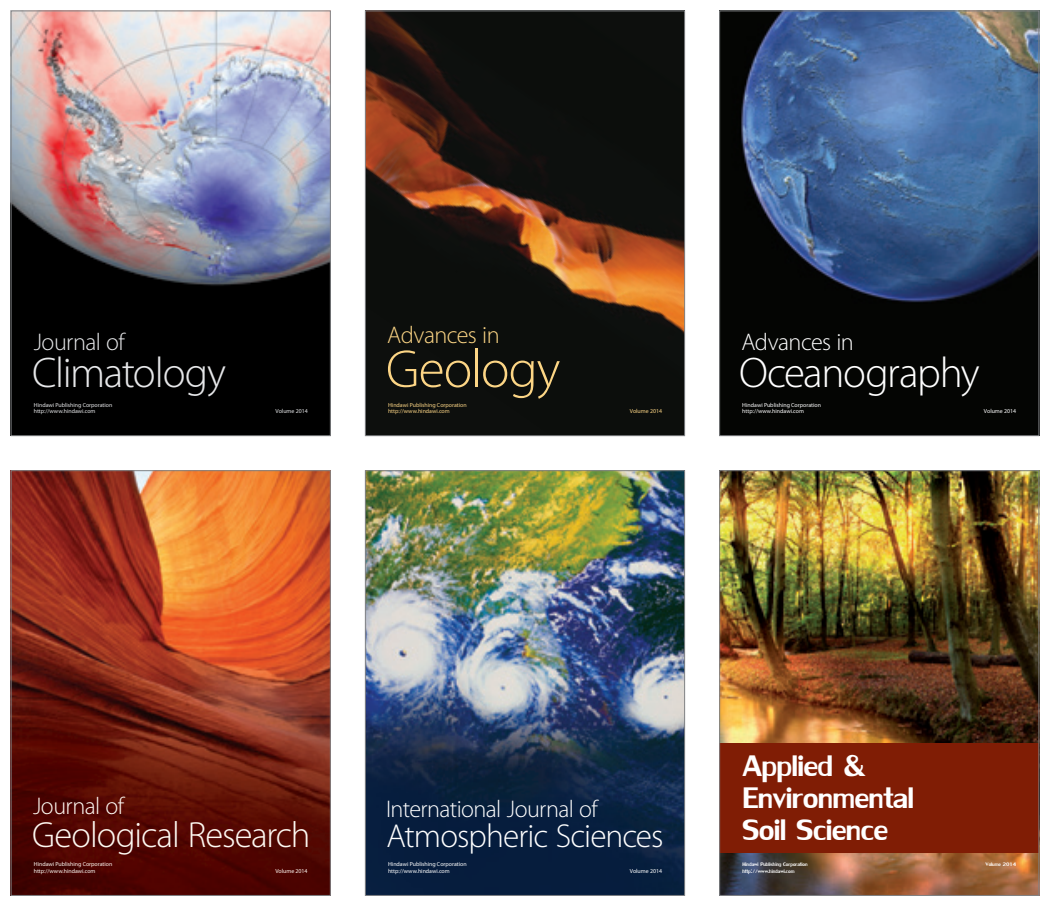
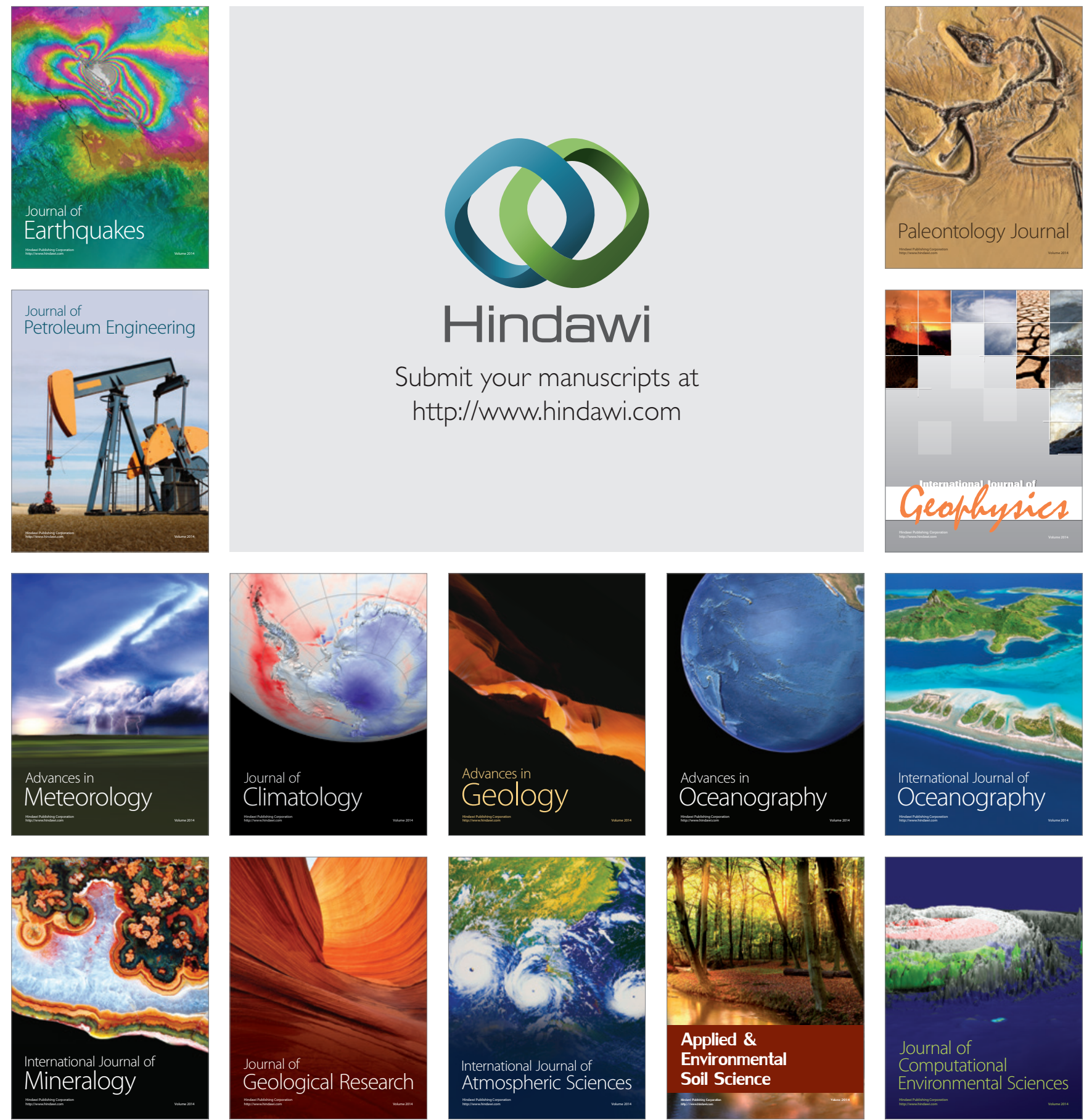